\title{
District-level analysis of climate vulnerability and household nutrition status among rural communities in Odisha, India
}

\author{
Arabinda Acharya ${ }^{1,2 *}$, Anup Kumar Das ${ }^{1,2}$ \\ ${ }^{1}$ Knowledge Management and Learning Expert, Bhubaneswar, Odisha, India \\ ${ }^{2}$ Deputy Director, TARINA Programme, CARE India Solutions for Sustainable \\ Development, Bhubaneswar, Odisha, India
}

\section{ARTICLE INFO}

Received: December 5, 2019

Accepted: January 20, 2020

Published: January 28, 2020

*CORRESPONDING AUTHOR

Dr. Arabinda Acharya, Knowledge Management and Learning Expert; CARE India Solutions for Sustainable Development, Eastern Hub Office, Plot No 372, Saheed Nagar, Bhubaneswar-750007, Odisha, India. arabinda@careindia.org

\section{CITATION}

Acharya A, Das AK. (2020). District-level analysis of climate vulnerability and household nutrition status among rural communities in Odisha, India. International Journal of Population Studies, 6(1):41-55. doi: 10.18063/ijps.v6i1.1069

Copyright: @ 2020 Acharya and Das. This is an Open-Access article distributed under the terms of the Creative Commons Attribution-Non Commercial 4.0 International License (http://creativecommons.org/ licenses/by-nc/4.0/), permitting all noncommercial use, distribution, and reproduction in any medium, provided the original work is properly cited.

\begin{abstract}
Good nutrition is the foundation of human well-being that leads to better health, effective engagement of the workforce, and productive lifestyle, resulting in higher income and an integrated development trajectory. This paper attempts to comprehend the impact of climate vulnerability on household nutrition status through agriculture production systems in Odisha, India. This study using secondary data estimates a composite index of climate vulnerability on the agriculture ecosystem in Odisha at the district scale. Results suggest that among all the districts in Odisha, Bhadrak (0.193) is the most vulnerable district followed by Sonepur (0.191) and Baudh (0.190). On the other hand, Mayurbhanj (0.099) is the least vulnerable district followed by Ganjam (0.103) and Sundargarh (0.105). The findings also suggest that there is a wide variation in vulnerability indicators among the districts in Odisha $(0.099$ - the lowest district value vs. 0.193 - the highest). The results of multivariate analysis evince that in households (both women and children) nutritional status, the composite value of "climate vulnerability" has a greater role in predicting the predictors in Odisha through the agriculture production system. The climate vulnerability has a positive and significant relationship with forest area $\left(\mathrm{r}=0.403^{*}\right)$, gross cropped area $\left(\mathrm{r}=0.489^{* *}\right)$, percent of scheduled caste population $\left(\mathrm{r}=0.510^{* *}\right)$, percent of urban area $\left(\mathrm{r}=0.427^{*}\right)$, and per-capita income $\left(\mathrm{r}=0.712^{* *}\right)$. The findings also signify that district-wise gross cropped area $(\mathrm{t}=3.01)$, average annual rainfall $(\mathrm{t}=4.05)$, area under irrigation $(\mathrm{t}=3.36)$, cropping intensity $(\mathrm{t}=3.60)$, and forest areas $(\mathrm{t}=1.81)$ play a more predictive role to determine the household nutritional status along with socioeconomic and health factors such as per-capita income ( $\mathrm{t}=1.8)$, urbanization ( $\mathrm{t}=1.91)$, and women's anemic status $(t=2.74)$. Drawing inferences from the empirical evidence, the study suggests that climate vulnerability has a much greater role in influencing household nutrition status, particularly with women and child nutrition through the agriculture production system. Appropriate policy level measures for climate-sensitive and adaptive action are the need of the hour to make agriculture production ecosystem contributes positively to nutrition status.
\end{abstract}

Keywords: Climate change, Climate vulnerability, Nutrition, India

This article belongs to the Special Issue: Environment and Population Dynamics in South Asia

\section{Introduction}

Good nutrition is a foundation of human well-being that leads to good health, effective engagement in the workforce, and productive lifestyle, resulting in higher income and an integrated development trajectory. Over the years, the burden of undernutrition and micronutrient deficiencies remains staggering across the globe with the regional disparity at the center. Research findings on public health reveal that better-nourished mothers can give 
birth to well-nourished children, and better-nourished children can keep themselves more engaged in productive work during their youth and adulthood (Global Nutrition Report, 2014). Proper nutrition averts death (particularly during childhood). It enables healthy growth of the body and the growth of cognitive skills to its full potential, without which life and livelihood become quicksand. Malnutrition is also responsible for ill-health than any other cause is (Global Nutrition Report, 2014). Malnutrition is a universal issue. Its burden remains unacceptably high, coupled with stunted progress all over the world. Children under age five face multiple burdens of malnutrition. Gender disaggregated data show that women have a higher propensity of a burden than men in certain forms of malnutrition, i.e., obesity and overweight. As per United Nations Children Fund (UNICEF) estimates, globally, 151 million children under age five are stunted, 50.5 million are wasted, 38.3 million are overweight, and a quintile million babies are born with the low birth weight each year. Nearly one of four adults $(38.9 \%)$ are overweight or having obesity, one-third of women in reproductive age have anemia, and a million women are still underweight (UNICEF, 2006). Poor nutrition and deficiency of vitamins and minerals in food plates result in physical disorders and higher susceptibility to several diseases (Horton and Steckler, 2013). The latest analysis available suggests that undernutrition is associated with three million child-deaths annually, which is almost half of child mortality globally (Global Nutrition Report, 2018). Nearly one-third of global stunted children (about 57 million) are living in India and the majority of them live in rural areas which are a matter of great policy concern.

Across the world, it has been well recognized that linking policies and investments on agriculture with improved health and sanitation have a potential impact on improving the household nutrition outcomes. Unfortunately, in India, the agriculture production system is still reeling under traditional staple grain fundamentalism. This has a limited scope to address the issues of undernutrition through available food systems. Black, Victora, Walker, et al. (2013) have found that agriculture has strong potential to influence the underlying determinants of nutrition outcomes by improving global food availability and access through enhancing household food security, dietary quality, income, and women's empowerment (Black, Victora, Walker, et al., 2013). In this backdrop, nutrition-sensitive agriculture interventions can be a potential source for ensuring positive nutritional outcomes by increasing the quality and availability of agricultural commodities, as well as the quality of food in terms of diet diversity, nutrient content, and food safety. As defined by UNICEF (1990), four main factors play a crucial role in determining the household nutrition status: (i) Availability and access to quality food; (ii) quality of feeding and caregiving practices; (iii) health of the surrounding environment, and (iv) access to health care services (UNICEF, 1990). Each of these determinants is a necessary but not a sufficient condition for proper nutrition at the household level. This paper attempts to comprehend the factors that are influencing the availability of and accessibility of quality food at the household level in Odisha, particularly from a climate vulnerability perspective. The study conceptualizes that the availability of quality food at the household level is affected by climate vulnerability, contributing partly to poor household nutrition outcomes.

\subsection{Relationship of Climate Vulnerability and Household Food and Nutrition Status}

Climate-induced variability has a significant contribution to the vulnerability quantum of biophysical as well as socioeconomic ecosystems. The biophysical ecosystem consists of mountains, rivers, forests, wetlands, etc., whereas socioeconomic ecosystem comprises the hill communities, coastal communities, agriculture, and animal husbandry, etc. Intergovernmental Panel on Climate Change (IPCC) defines "vulnerability" as the "propensity or predisposition of a system to be adversely affected." It is an intrinsic property of a system which includes "sensitivity," i.e., susceptibility to harm, exposure to potential hazards, and "lack of adaptive capacity" (IPCC, 2014). As per IPCC report 2014, global climate change will reduce agricultural production by $2 \%$ every decade while the demand for food will increase by $14 \%$ every decade until 2050. Yields of primary crops will face an average decline of $8 \%$ for Africa and South Asia by 2050. The decrease in food production and a reduction in nutritional quality could increase child malnutrition up to $20 \%$ by 2050 and additional 600 million people will suffer from hunger due to climate change (IPCC, 2014). The poorest countries and regions are generally most susceptible to damage caused by weather extremes and climate variability. Countries with a higher human development index (HDI) are less likely to be affected by the ill effects of floods, droughts, and cyclones (Malik, Awan and Khan, 2012; Patt, Tadross, Nussbaumer, et al., 2010). Among all the countries of the world, India is quite vulnerable because; more than three of ten poor people live in India, $70 \%$ of its inhabitants are engaged in agriculture, 40 million hectares of land susceptible to floods, $68 \%$ of its agricultural land vulnerable to drought, long coastline prone to cyclones, and rising annual mean temperature (GOI, 2004; GoO, 2017; Radhakrishnan, Sivaraman, Jena, et al., 2017). The State of Odisha has been experiencing distinct weather variability resulting in significant negative effects on agriculture production, thus elevating the prospect of hunger and malnutrition. Odisha features as one of the most vulnerable states in India to climate change regime and the occurrence of natural disasters, including floods, cyclones, drought, and heatwaves (Ray-Bennett, 2009; GOI, 2012; GoO, 2016; Patel, 2016). The geographic location and 
climatic conditions of Odisha make it conducive for witnessing in multiple disasters due to this Sharma, Mohanty, and Islam, (2016) observes that the State Odisha is the disaster capital of India (Sharma, Mohanty, and Islam, 2016). Using 45 years of data for seven selected crops (panel data) of Odisha Das (2017) observed that changing climate, particularly at the rainfall and temperature level, has significant impacts on the crop production in Odisha (Das, 2017). Research studies using panel regression analysis found that climate change has a significant influence on the agriculture production system in Odisha (Mishra and Sahu, 2014; Mishra, Sahu and Sahu, 2015; Patel, Mathew, Nanda, et al., 2020).

IPCC (2007) working Group-II estimates that changing climate in India will lead to a drop in wheat production by 4-5 million tones, 4-35\% reduction in rice yields, and negative impacts on livestock (WG-II, IPCC-2007). The panel also highlights a $10-30 \%$ decline in freshwater supply due to floods and droughts, which have significant negative impacts on livelihoods and biodiversity. Rising temperature due to climate change seems to increase the probability of higher morbidity and mortality from heat stress and vector or water-borne diseases. Rapid variation in rainfall intensity and occurrences resulting in more frequent floods and droughts will also contribute to higher morbidity and mortality. Weather variability and climate-induced stress result in low land utilization and productivity. In this way, it is marked with high unpredictable production rates from a unit of input invested. Increasing the probability of crop loss or production failure due to pest attack, pathogens, poor weed, and plant growth management is also marked with less availability of physical labor for agriculture. Besides these, the impact of crop production on the dynamic balance of biophysical resources (soil quality, water availability, sunlight, and temperature suitability) cannot be ignored. Samuel, Smith, and Guth (2017). observed that climate change has significant influence on each of those above discussed dimensions of agricultural production (Samuel, Smith and Guth, 2017).

\subsection{Research Objectives}

Climate change has a paramount role in changing household nutrition patterns by influencing agriculture production system and access to the availability of quality food at the household level, and this can be deduced by reviewing various research documents. Changing climate will lead to a change in temperature pattern. Thus, the agriculture ecosystem will face severe consequences of weather stress in the form of drought, erratic rainfall, low pressure, excess or scanty rain, flood, severe pest attack on plant, the incidence of pathogens, poor weed management, less growth of the plant, nutrient loss of the crop, inadequate availability of the agriculture labor and direct impact on the livestock reproduction system. Ultimately less agriculture production and productivity, inadequate availability of nutritious food and quality diet at household level will lead to poor household-level nutrition outcomes. Hence, climate change affects food production and consequently, the household food and nutrition status. In this backdrop, the following questions have emerged, is there any significant impact of climate vulnerability on household food and nutrition status in Odisha through agriculture production pathways system? Do higher climate-vulnerable districts have low household-level nutrition indicator performances, particularly on women and child nutrition? Is there any relationship that exists between climate vulnerability and household nutrition?

The study examines to understand the role of climate vulnerability on the agricultural ecosystem and its cascading impacts on household nutrition status in Odisha to address the questions raised in the above section. The specific objectives of the study are to (1) rank the districts of Odisha based on their climate vulnerability extent with reference to agriculture production system by developing a composite index and (2) comprehend the linkage of climate vulnerability with household nutrition status, particularly among children under age five and women in reproductive age group through an agriculture production system.

\subsection{Nutrition Status of Odisha - A Brief Sketch}

Odisha is in the eastern part of India with a long coastline bordering the Bay of Bengal. As per Census (2011), the state accounts for approximately $3.46 \%$ of the total population of the country. For administrative purposes, Odisha is divided into three revenue divisions and 30 districts with a population of about 42 million (2011 Census). It has a cultivated area of 6.180 million hectares with highly skewed operational landholdings. Of this, more than $91 \%$ of areas belong to small and marginal farmers and the average size of landholding is 1.04 hectares (GoO, 2017). In the recent past, Odisha has progressed considerably on nutrition indices being a signatory to the global commitments to end malnutrition. As per the latest round of National Family Health Survey (NFHS-4) (2015-2016), one-third (34.1\%) of children under age five in Odisha are stunted, which has reduced from 45\% in 2005-2006. More than three (34.4\%) of ten children in the age as a mentioned earlier group are underweight, and one-fifth of the children are wasted. It is also found that one of each four $(26.4 \%)$ women in the reproductive age group are reported having below-average body mass index and more than half (51\%) is anemic. Approximately half (47.6\%) of pregnant women aged 15-49 years are also anemic (NFHS-4, 
2015-2016). Further, tracking the global nutritional targets, as mentioned in the World Health Assembly, it is estimated that the pace of improvement in nutrition indicators is languid in India. Odisha must travel miles to reach to the WHA global nutritional targets set so far for 2025. Considering NFHS-4, 2015-2016 has been considered the base year for the study. It is found that of six global nutrition targets, India and Odisha can manage to achieve only four in the prescribed timeline of 2025. These four indicators are stunting, wasting, and anemia among women in the reproductive age group and exclusive breastfeeding in the first 6 months.

\section{Data and Methods}

\subsection{Data sources}

In this study, data have been collected from various secondary sources such as the Census of India 2011, Annual Health Survey-III, 2012-2013, Economic Survey-2013-2014, Agriculture Statistics, India Meteorological Department Data, Annual Year Book of Odisha Ground Water, and other published sources. All the collected data have been used for assessing the district-wise climate vulnerability of Odisha. More importantly, the study makes use of these datasets to construct the district level climate vulnerability status based on three parameters (i) sensitivity, (ii) exposure, and (iii) adaptive capacity on vulnerability to affect the agriculture production. These indicators are broadly "biophysical" or "socioeconomic" in nature. In the present analysis, we have identified 13 indicators pertaining to biophysical, socioeconomic, and demographic factors. Five indicators were chosen under the biophysical category, whereas eight indicators were identified under the socioeconomic category for calculations to estimate the vulnerability. The rationality of selection of the indicators is drawn from their inter-relationship available sources in reference to the years and weights allotted, which is presented in Table 1.

\subsection{Measurements and Methods}

\subsubsection{Household nutrition indicators}

The fourth round of NFHS (2015-2016) published data is used for deriving the household nutrition status. Until date, the NFHS has been conducted four times in India. The first survey refers to the year 1992-1993 followed by a second in 1998-1999, third in 2005-2006, and the latest in the year 2015-2016. This survey is a storehouse of data for several health indicators, namely, fertility, infant and child mortality, the practice of family planning, maternal and child health, reproductive health, nutrition, anemia, utilization, and quality of health and family planning services on national and states level separately. The NFHS is a large-scale, multi-round survey conducted in a representative sample of households throughout India. The survey is modeled in the line of "Demographic and Health Survey" conducted in many countries around the world. For understanding the household nutrition status in the study, three nutrition indicators have been used, i.e., two from child nutrition and one from women nutrition category. Weight-for-height (Wasting) children (0-5 years) and anemia children (6-59 months) from child nutrition category and anemia - women (15-49 years) are from women nutrition category. For child nutrition, wasting or weight-for-height is defined as an index for the measurement of body mass in relation to body height that describes current nutrition status. It provides an estimate for acute undernutrition and represents the failure to receive adequate nutrition in the period immediately preceding the survey and maybe the result of inadequate food intake or a recent episode of illness-causing loss of weight and the onset of malnutrition. Anemia is a condition that is marked by low levels $(<11.0$ for children $6-59$ months and pregnant women age $15-49$ years and $<12.0$ for non-pregnant women age 15-49 years) of hemoglobin content in the blood. Iron is a crucial component of hemoglobin and iron deficiency is estimated to be responsible for half of all anemia globally. Anemia is a severe concern for children because it can impair cognitive development, resulting in stunted growth, and increase morbidity from infectious diseases.

\subsubsection{Normalization of vulnerable indicators}

To comprehend climate vulnerability and its impact on household nutrition status, it is essential to develop an indicator that is quantifiable, comprehensive, and can establish the relationship. Toward this attempt, the study estimates the climate vulnerability using "Composite Index" method, factoring in information from various secondary sources. The composite index is computed based on the dimensional relationship of the indicators with climate vulnerability and agriculture production system. Before estimating the composite index, we have normalized each indicator to reduce its variability as different indicators have different measurement units. For example, the per capita income is defined in terms 
of rupees, whereas the area under forest cover is defined as the percentage of total geographical area. More importantly, the normalization process provides us with the opportunity to estimate the single value and to comprehend the relationship thereof. The selection of the indicators for preparing a composite index depends on the nature of the relationship of the respective indicator with the predictor.

Let $\mathbb{x}_{i j}$ represent the value of the $i^{\text {th }}$ climate vulnerability indicator in the $j^{\text {th }}$ district if $\mathbb{x}_{i j}$ is positively associated with the climate vulnerability $(i=1,2,3, \ldots \ldots, 10 ; j=1,2, \ldots \ldots \ldots, 10)$. Let us write the equation as:

$$
Y_{i j}=\frac{X_{i j}-\operatorname{Min}_{j} X_{i j}}{\operatorname{Max}_{j} X_{i j}-\operatorname{Min}_{j} X_{i j}}
$$

Where $\operatorname{Min}_{j} \mathbb{x}_{i}$ and $\operatorname{Max} \mathbb{x}_{j}$ are the minimum and maximum of $\mathbb{x}_{i j}$, respectively.

However, if $\mathbb{x}_{i j}$ is negatively associated with climate vulnerability, equation (1) can be written as:

$$
Y_{i j}=\frac{\operatorname{Max}_{j} X_{i j}-X_{i j}}{\operatorname{Max}_{j} X_{i j}-\operatorname{Min}_{j} X_{i j}}
$$

Scaling the dimension index values, $\mathbb{y}_{i j}$ vary from zero (0) to one (1), where 0 indicates the lowest vulnerability and 1 indicates the highest vulnerability. In all parameters, no normal or goalpost value has been defined. The observed maximum value of parameters has been taken as the goalpost value, and the observed minimum value is taken as a minimum from the matrix of scaled dimension values, $Y=\left\{\left(Y_{i j}\right)\right\}$. In this process, we constructed the "Composite Index of Climate Vulnerability" for different districts of Odisha. The above-mentioned method is quite like the United Nations Development Programme's HDI. The Ministry of Science and Technology also uses the method - Government of India under the National Mission for Sustaining the Himalayan Ecosystem as part of National Action Plan on Climate Change to develop the Climate Vulnerability Assessment of Indian Himalayan Region (DST-GoI, 2018-2019). Further, we have assigned the weights of the indicators using principal component analysis. The weight is also generated in view of the importance of indicator on determining climate vulnerability and its effect on agriculture production. While assigning the weight, it was ensured that the weight or proportion assigned to all the indicators add up to " 1 ;" where, the weight $W$, of the $i^{\text {th }}$ indicator, varies inversely as the variation in the respective indicator of climate vulnerability status subject to the condition:

$$
0<W_{i}<1 \text { and } W_{1}+W_{2}+W_{3}+\ldots \ldots . .+W_{m}=1
$$

Such that,

$$
W_{i}=\frac{K}{\sqrt{\text { Variance }_{i}}}
$$

Where,

$$
K=\left[\sum_{i=1}^{m} \frac{1}{\sqrt{\text { Variance }_{i}}}\right]^{-1}
$$

The choice of weights in this manner is taken up to ensure that large variations in any one of the indicators will not unduly dominate the contribution of the rest and distort the inter-group comparisons across the districts. To obtain a weighted average of a composite aggregated index value, we have added the total weighted value of each indicator of the same district and the sum is divided by the total number of indicators of the same district. The signs of the indicators (+ve or $-\mathrm{ve}$ ) are assigned accordingly based on the fact whether each of them is contributing to an increase in or decrease in climate vulnerability.

\subsubsection{Methods}

To investigate the effects, we have used a correlation matrix and the techniques of multiple regression analysis. Under multiple regressions, six different models (four models for child nutrition and two for women nutrition) are used to find out the association. Following two types of regression models are worked out to identify the factors responsible for determining the household nutritional status in Odisha. We define the (HNS) Household Nutrition Status as listed below with three indicators, BPI as Biophysical Indicators (five indicators as mentioned in Table 1), SEI defined as 
Table 1. The rationality of selection of the indicator and its relationship with vulnerability.

\begin{tabular}{|c|c|c|c|c|}
\hline \multirow[t]{2}{*}{ Sl. No. } & Indicators and dimension () & Relationship with vulnerability & Data sources & Weight \\
\hline & \multicolumn{4}{|l|}{ Biophysical } \\
\hline 1 & $\begin{array}{l}\text { Percentage of the area under } \\
\text { forest cover 2016-2017 (-) }\end{array}$ & $\begin{array}{l}\text { Forests provide safeguard to ecological processes, provide } \\
\text { biophysical stability and alternate livelihood options, and enhance } \\
\text { the adaptive capacity. }\end{array}$ & Census of India 2011 & 0.28 \\
\hline 2 & $\begin{array}{l}\text { Average Annual Rainfall in } \\
\text { millimeter - 2007-2016(-) }\end{array}$ & $\begin{array}{l}\text { Increasing average rainfall increases agricultural production and } \\
\text { raises the adaptive capacity }\end{array}$ & $\begin{array}{l}\text { India Meteorological } \\
\text { department }\end{array}$ & 0.18 \\
\hline 3 & $\begin{array}{l}\text { Gross cropped area in hectare } \\
2013-2014(-)\end{array}$ & $\begin{array}{l}\text { Gross cropped area depicts the available land for cultivation and } \\
\text { sensitivity to climate vulnerability }\end{array}$ & Agriculture statistics & 0.16 \\
\hline 4 & $\begin{array}{l}\text { Cropping intensity in } \\
\% 2013-2014(-)\end{array}$ & $\begin{array}{l}\text { It represents the frequently available land for cultivation which } \\
\text { has direct sensitivity with food production and vulnerability }\end{array}$ & Agriculture statistics & 0.09 \\
\hline \multirow[t]{2}{*}{5} & $\begin{array}{l}\text { The area under irrigation in } \\
000 \text { ' hectare } 2013-2014(-)\end{array}$ & $\begin{array}{l}\text { Availability of irrigation facility has a direct link with food } \\
\text { production and sensitivity to the climate vulnerability }\end{array}$ & $\begin{array}{l}\text { Annual report } \\
\text { groundwater }\end{array}$ & 0.09 \\
\hline & Socioeconomic & & & \\
\hline 6 & Population density in $2011(+)$ & Pressure on available natural resources increases sensitivity. & Census & 0.05 \\
\hline 7 & $\%$ of SC population in $2011(+)$ & Their adaptive capacity toward vulnerability is low & Census & 0.01 \\
\hline 8 & $\%$ of ST population in $2011(+)$ & Their adaptive capacity toward vulnerability is still low & Census & 0.01 \\
\hline 9 & $\%$ of female literacy in $2011(-)$ & Educated women household have better adaptive capacity & Census & 0.04 \\
\hline 10 & $\%$ of urban area in $2011(-)$ & $\begin{array}{l}\text { Rapid urbanization and development quick depletion of natural } \\
\text { resources increases the sensitivity of vulnerability }\end{array}$ & Census & 0.01 \\
\hline 11 & $\begin{array}{l}\text { Infant mortality rate } \\
2012-2013(+)\end{array}$ & $\begin{array}{l}\text { It is synonymous of overall development indicator. Higher the } \\
\text { value implies a lack of adaptive capacity. }\end{array}$ & AHS & 0.02 \\
\hline 12 & $\begin{array}{l}\text { Per capita income in } \\
\text { rupees (NDDP) } 2013-2014(-)\end{array}$ & $\begin{array}{l}\text { A direct indicator representing the inherent sensitivity of people } \\
\text { in a region }\end{array}$ & Economic survey & 0.00 \\
\hline 13 & $\begin{array}{l}\text { Average man-days employment } \\
\text { generated under MGNREGA } \\
2013-14(-)\end{array}$ & $\begin{array}{l}\text { Provides alternate sources of income and enhances the adaptive } \\
\text { capacity. }\end{array}$ & MGNREGS & 0.00 \\
\hline
\end{tabular}

"()" Sign under parenthesis is the dimension of the indicator

socioeconomic indicators (eight indicators as listed in Table 1), and CVCV acronym as Composite Value of Climate Vulnerability. District wise detailed value of these indicators are provided in Table A1. As mentioned above, three independent models have been run separately using Statistical Package for the Social Science version-21 to examine the association of climate vulnerability with household nutrition status.

\section{Results}

The results of this study are presented in two parts. The extent and variation of climate vulnerability among districts in Odisha are interpreted by computing a composite index, ranking the individual index values and then through categorizing the ranks associated with the indexes. Association of climate vulnerability with household nutrition is comprehended through multivariate analysis in the second stage. The study computes the climate vulnerability index notably, the vulnerability about agriculture production using various secondary published data sources, as mentioned in Table 2, considering both biophysical as well as socioeconomic factors. While estimating the weighted scores of the climate vulnerability in Odisha, it is found that among the districts, Mayurbhanj (0.099) is the least vulnerable district followed by Ganjam (0.103) and Sundergarh (0.105). On the other hand, Bhadrak (0.193) is the most vulnerable district followed by Sonepur (0.191) and Baudh (0.190). The study also found that around 37\% (11 of 30) of districts in Odisha are categorized under a high climate vulnerability segment, $53 \%$ are in medium bracket followed by $10 \%$ in low segment. The details of the results are presented in Table 2 .

\subsection{Impact of Climate VuInerability on Household Nutrition Status}

Before applying the multivariate regression analysis, it is crucial to comprehend the cause and effect relationship of climate vulnerability and household nutrition status. It is observed that direct relationships between household nutrition status and climate vulnerability in Odisha, although the latter has a significant role through the agriculture production 
Table 2. District-wise climate vulnerability in Odisha, India.

\begin{tabular}{|c|c|c|c|}
\hline Districts & Climate vulnerability index & Rank & $\begin{array}{l}\text { Rank category } 0-0.106=\text { Low, } 0.115-0.170= \\
\text { Medium, } 0.171-0.193=\text { High }\end{array}$ \\
\hline Mayurbhanj & 0.099 & 1 & Low \\
\hline Ganjam & 0.103 & 2 & Low \\
\hline Sundargarh & 0.105 & 3 & Low \\
\hline Angul & 0.106 & 4 & Medium \\
\hline Keonjhar & 0.115 & 5 & Medium \\
\hline Kandhamal & 0.115 & 6 & Medium \\
\hline Sambalpur & 0.126 & 7 & Medium \\
\hline Khordha & 0.131 & 8 & Medium \\
\hline Cuttack & 0.136 & 9 & Medium \\
\hline Koraput & 0.141 & 10 & Medium \\
\hline Kalahandi & 0.144 & 11 & Medium \\
\hline Dhenkanal & 0.147 & 12 & Medium \\
\hline Jharsuguda & 0.158 & 13 & Medium \\
\hline Bolangir & 0.159 & 14 & Medium \\
\hline Rayagada & 0.159 & 15 & Medium \\
\hline Gajapati & 0.160 & 16 & Medium \\
\hline Jajpur & 0.169 & 17 & Medium \\
\hline Jagatsinghpur & 0.169 & 18 & Medium \\
\hline Balasore & 0.170 & 19 & Medium \\
\hline Nuapada & 0.171 & 20 & High \\
\hline Nabarangpur & 0.171 & 21 & High \\
\hline Nayagarh & 0.172 & 22 & High \\
\hline Deogarh & 0.173 & 23 & High \\
\hline Malkangiri & 0.174 & 24 & High \\
\hline Baragarh & 0.181 & 25 & High \\
\hline Kendrapara & 0.181 & 26 & High \\
\hline Puri & 0.185 & 27 & High \\
\hline Boudh & 0.190 & 28 & High \\
\hline Sonepur & 0.191 & 29 & High \\
\hline Bhadrak & 0.193 & 30 & High \\
\hline
\end{tabular}

Source: Computed by authors using secondary data sources

system. The high climate-vulnerable districts are found to have a greater number of wasted children aged 0-5 years, anemic among children aged 6-59 months, and anemic women aged 15-49 years. Findings also reveal that districts having a high climate vulnerability burden also reveal high household malnutrition burdens, particularly among women and children. The details of the analysis are presented in Table 3.

For better comprehending the relationship of climate vulnerability (through agriculture production system) concerning household nutrition status, the study uses a correlation matrix, where the degree of relationship of the variables has been observed. It is also found that climate vulnerability has a strong positive significant association with district-wise areas under forest coverages $\left(\mathrm{r}=0.403^{*}\right)$, gross cropped area $\left(0.489^{*}\right)$, the area under irrigation facilities $\left(0.466^{* *}\right)$, and socialeconomic factors such as percentage of scheduled caste population $\left(0.510^{* *}\right)$, urbanization $\left(0.427^{*}\right)$, per-capita income $\left(0.712^{* *}\right)$, and average numbers of men-for-days employment generated under MGNREGS $\left(0.688^{* *}\right)$. The results of the correlation matrix portray that the climate vulnerability of Odisha has a close inter-association with the agriculture production system through the gross cropped areas and area under forest coverage. The detailed results of the correlation 
Table 3. District-wise climate vulnerability and household nutrition status in Odisha, India.

\begin{tabular}{|c|c|c|c|c|c|}
\hline Districts & Rank & $\begin{array}{l}\text { Rank category } 0-0.106=\text { Low, } \\
0.115-0.170=\text { Medium, } 0 . \\
171-0.193=\text { High }\end{array}$ & Weight-for-height (wasting) & $\begin{array}{c}\text { \% of Children 6-59 } \\
\text { months who are having } \\
\text { anemic }\end{array}$ & $\begin{array}{c}\% \text { of women } \\
15-49 \text { years who are } \\
\text { having anemic }\end{array}$ \\
\hline Mayurbhanj & 1 & Low & 17.2 & 34.5 & 42.4 \\
\hline Ganjam & 2 & Low & 16.4 & 37.4 & 41.3 \\
\hline Sundargarh & 3 & Low & 31.4 & 75.3 & 71.4 \\
\hline Angul & 4 & Medium & 21.6 & 37.4 & 44.0 \\
\hline Keonjhar & 5 & Medium & 19.0 & 32.7 & 40.5 \\
\hline Kandhamal & 6 & Medium & 23.1 & 42.7 & 52.7 \\
\hline Sambalpur & 7 & Medium & 22.3 & 75.0 & 69.2 \\
\hline Khordha & 8 & Medium & 13.8 & 19.0 & 45.3 \\
\hline Cuttack & 9 & Medium & 9.1 & 18.9 & 37.8 \\
\hline Koraput & 10 & Medium & 28.5 & 71.4 & 63.3 \\
\hline Kalahandi & 11 & Medium & 24.8 & 67.2 & 68.7 \\
\hline Dhenkanal & 12 & Medium & 19.0 & 39.4 & 39.4 \\
\hline Jharsuguda & 13 & Medium & 24.8 & 67.1 & 69.2 \\
\hline Bolangir & 14 & Medium & 26.1 & 67.3 & 61.1 \\
\hline Rayagada & 15 & Medium & 23.1 & 49.8 & 55.4 \\
\hline Gajapati & 16 & Medium & 18.4 & 57.9 & 58.5 \\
\hline Jajpur & 17 & Medium & 9.1 & 18.9 & 37.8 \\
\hline Jagatsinghpur & 18 & Medium & 12.6 & 23.4 & 35.8 \\
\hline Balasore & 19 & Medium & 18.0 & 28.6 & 41.1 \\
\hline Nuapada & 20 & High & 26.4 & 63.9 & 64.0 \\
\hline Nabarangpur & 21 & High & 36.0 & 71.9 & 71.5 \\
\hline Nayagarh & 22 & High & 17.5 & 26.5 & 39.8 \\
\hline Deogarh & 23 & High & 19.9 & 30.0 & 42.6 \\
\hline Malkangiri & 24 & High & 32.5 & 72.2 & 71.3 \\
\hline Baragarh & 25 & High & 24.2 & 68.8 & 68.8 \\
\hline Kendrapara & 26 & High & 12.3 & 28.7 & 42.3 \\
\hline Puri & 27 & High & 12.1 & 29.2 & 44.3 \\
\hline Boudh & 28 & High & 22.5 & 44.1 & 49.9 \\
\hline Sonepur & 29 & High & 22.3 & 75.0 & 69.2 \\
\hline Bhadrak & 30 & High & 15.3 & 22.7 & 43.5 \\
\hline
\end{tabular}

Source: Computed by authors using data from secondary sources

matrix have been presented in Table 4 .

The results of multiple regression analysis have been documented in Table 5. As mentioned above for better comprehension, under each dependent variable, two separate models were created. First is one to one matching of the composite values with dependent variables, and the second one is the matching of independent variables with all associating factors except composite values. In this process, six models were made to run for three identified predictors which relate to household nutrition outcomes. The results of the multivariate analysis suggest that household nutrition status, particularly child nutrition indicators (wasting and childhood anemia), are associated significantly with mother's anemic status, literacy level, and household's economic and social caste composition. The child nutrition status relates not only to socioeconomic factors but also to biophysical factors such as district's predisposition to gross cropped area, percentage of the area having forest coverage, annual rainfall, and irrigation facility.

Similarly, the study also finds that household women nutrition status is also influenced by household's socioeconomic attributes such as women's social category, level of urbanization, and biophysical factors such as cropping intensity. Ironically, 


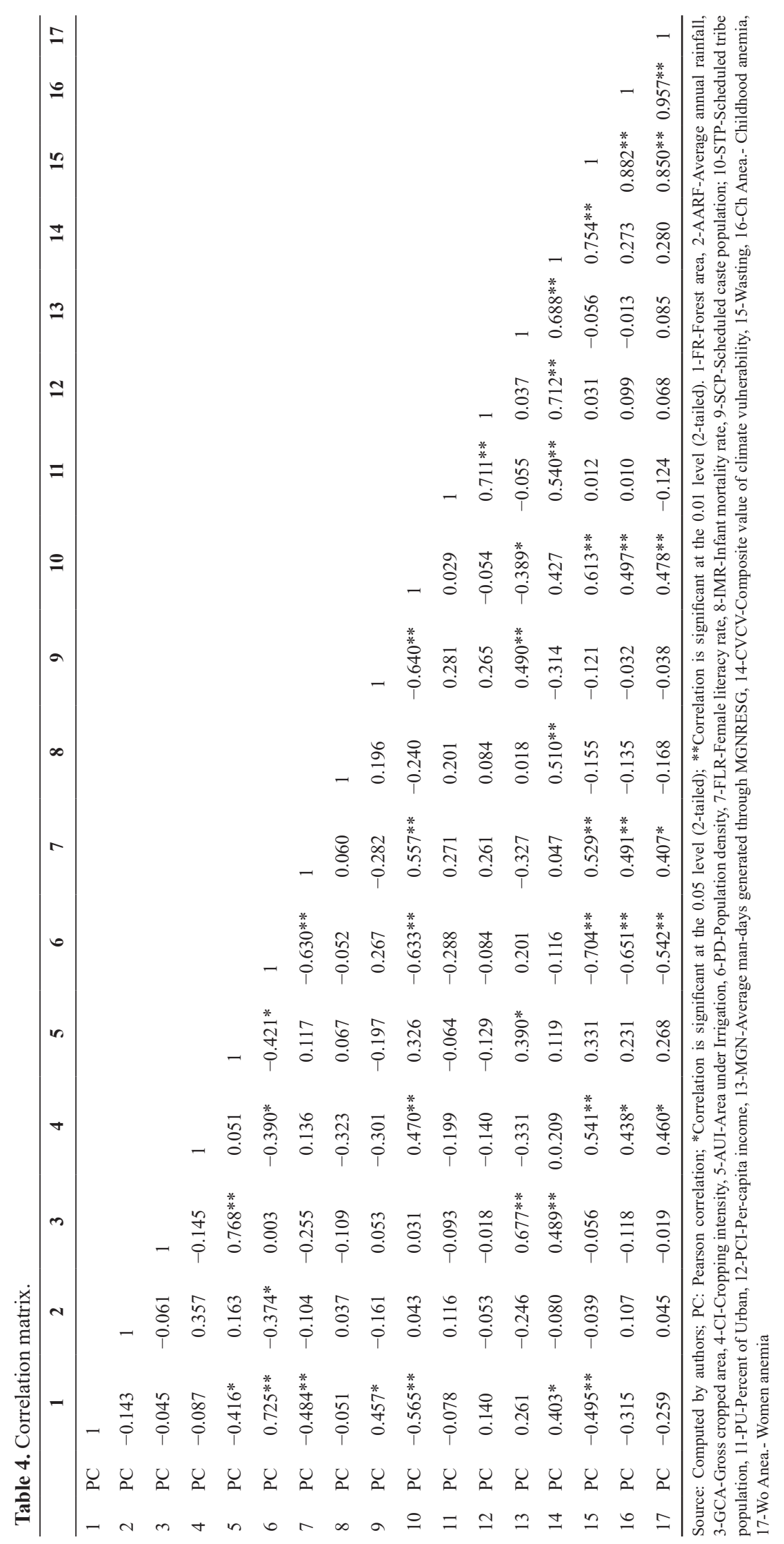


the study also finds that in household (both women and children) nutrition parameters, the composite value of the climate vulnerability index does not have much role in predicting the predictors. Of course, the individual covariates play a more predictive role to understand the role of climate vulnerability on household nutrition status. Similarly, the findings also reveal that gross cropped area, availability of forest areas, and average annual rainfall are negatively correlated with household child wasting and positively associated with area under irrigation and cropping intensity. Similarly, among biophysical factors, within the household, women's nutrition status is more governed by forest area and to some extent, with the cropping intensity. The estimates of these variables are statistically significant, with expected signs and the results that are presented in Table 5.

\section{Discussions}

This study highlights the role of climate vulnerability and its impact on household nutrition status through agriculture production systems in Odisha. The districts of Odisha have different agro-climatic zones and varied socioeconomic conditions. The composite index value shows that climate vulnerability has a significant impact on the agriculture production ecosystem in Odisha, considering both biophysical as well as socioeconomic factors. The study observed that around two-third number of districts in Odisha are effected by climate vulnerability either in terms of a high or medium category where $70 \%$ of the population depends on agriculture as their primary source of food and livelihood (GOI, 2012; GoO, 2016). Unfortunately, the agriculture production ecosystem is widely affected by various climateinduced vulnerabilities. Many past studies have documented the same (Mishra, 2007; Chhotray and Few, 2012; GoO, 2016; Duncan, Tompkins, Dash, et al., 2017; Patel, Mathew, and Nanda, 2019; Patel, Mathew, Nanda, et al. 2020). This vulnerability not only affects agriculture production systems but also impacts nutrition outcomes of the household in terms of creating a scarcity of food, particularly nutrient-rich quality food for the agriculturally dependent households.

Table 5. Results of ordinary least square regression.

\begin{tabular}{|c|c|c|c|c|c|c|c|c|c|c|c|c|}
\hline \multicolumn{13}{|c|}{ Dependent variable: Household nutritional status } \\
\hline \multirow[t]{2}{*}{ Covariates } & \multicolumn{4}{|c|}{ Wasting } & \multicolumn{4}{|c|}{ Childhood anemia (0-59 m) } & \multicolumn{4}{|c|}{ Anemia among women in $15-19$ years } \\
\hline & B & t-test & B & t-test & B & t-test & B & t-test & B & t-test & B & t-test \\
\hline FA & - & - & -0.73 & $-1.8^{* * *}$ & - & - & 0.52 & 1.4 & - & - & -0.67 & -1.4 \\
\hline AARF & - & - & -1.5 & $-4.1^{*}$ & - & - & -0.21 & -0.62 & - & - & -0.09 & -0.16 \\
\hline GCA & - & - & -2.5 & $-3.1^{*}$ & - & - & -0.58 & -0.81 & - & - & -0.76 & -0.78 \\
\hline CI & - & - & 0.98 & $3.6^{*}$ & - & - & -0.29 & -1.2 & - & - & 0.54 & 1.3 \\
\hline AUI & - & - & 2.1 & $3.4 *$ & - & - & 0.38 & 0.69 & - & - & 0.52 & 0.6 \\
\hline PD & - & - & -0.8 & -1.5 & - & - & -1.1 & $-2.2^{* *}$ & - & - & 0.76 & 1.3 \\
\hline FLR & - & - & -0.5 & -1.4 & - & - & -0.12 & -0.37 & - & - & -0.06 & -0.17 \\
\hline IMR & - & - & -0.4 & -1.6 & - & - & -0.24 & -1.1 & - & - & 0.6 & 0.27 \\
\hline SCP & - & - & 0.8 & 1.7 & - & - & 0.6 & 0.14 & - & - & 0.39 & 0.84 \\
\hline STP & - & - & 0.3 & 0.8 & - & - & -0.14 & -0.39 & - & - & 0.53 & 1.34 \\
\hline PU & - & - & -0.02 & -0.3 & - & - & 0.3 & 0.66 & - & - & -0.86 & $-1.9^{* *}$ \\
\hline PCI & - & - & 0.4 & 0.87 & - & - & -0.23 & -0.57 & - & - & 0.72 & $1.8^{* * *}$ \\
\hline MGN & - & - & 0.6 & 0.91 & - & - & -0.37 & -0.67 & - & - & 1.04 & $1.8^{* * *}$ \\
\hline $\mathrm{CVCV}$ & 0.036 & 0.29 & - & - & 0.007 & 0.104 & - & - & 0.049 & 0.69 & - & - \\
\hline Wasting & - & - & - & - & - & - & - & - & - & - & -0.24 & -0.81 \\
\hline Ch Anea & - & - & - & - & - & - & - & & 0.912 & $7.6^{*}$ & 0.99 & $5.7^{*}$ \\
\hline Wo Anea & 0.849 & $7.9^{*}$ & 0.36 & 2.7 & 0.95 & $16.4^{*}$ & 0.89 & $7.7 *$ & - & - & - & - \\
\hline Constant & -0.265 & & 0.5 & 0.6 & -0.046 & -0.096 & 0.84 & 1.2 & -0.35 & -0.69 & -1.1 & -1.4 \\
\hline Adjusted $\mathrm{R}^{2}$ & 0.71 & & 0.91 & & 0.91 & & 0.93 & & 0.91 & & 0.92 & \\
\hline
\end{tabular}

$* * * 0<P<0.10, * * 0<P<0.05, * 0<P<0.001$. Source: Author's Computed; FR: Forest area, AARF: Average annual rainfall, GCA: Gross cropped area, CI: Cropping intensity, AUI: Area under irrigation, PD: Population density, FLR: Female literacy rate, IMR: Infant mortality rate, SCP: Scheduled caste population, STP: Scheduled tribe population, PU: Percent of Urban, PCI: Per-capita income, MGN: Average man-days generated through MGNRESG, CVCV: Composite value of climate vulnerability, Ch Anea.: Childhood anemia, Wo Anea.: Women anemia 
The results of the composite value computation validate that Mayurbhanj district is the least vulnerable, although the district has the highest percentage of tribal population. A high concentration of tribal population is often characterized as a low socioeconomic indicator but for better biophysical factors. Particularly the fact that the district is situated in the northcentral region having excellent irrigation facilities, the majority of land resources covered under various crops (higher gross cropped areas). It signifies the district's low climatic vulnerability toward agriculture production. Similarly, Ganjam, although the district is in the coastline of the state and is possess vast stretches of flood-plain areas with ample irrigation facilities and less concentration of tribal population. The district is found to be faring better in terms of agriculture production ecosystem.

On the other hand, Bhadrak is the most vulnerable district having low social and economic attributes along with biophysical factors. This district, like Ganjam, is also located in the coastline of the State. However, frequent natural disasters such as flood and cyclone compel the district to face high climate-induced vulnerability in agriculture ecosystem management. Districts such as Sonepur and Boudh tell similar stories. Although these two districts' geolocational position is a central part of the State historically, these two districts have recorded low socioeconomic parameters with a few portions of land left out for cultivation and frequent occurrence of natural disasters, particularly drought. Often these districts encounter long drought spells. The analysis in the study has also resulted low scores in both biophysical as well as socio-economic attributes for these districts despite having significant forest coverage. These are the districts that are characterized with few areas available for cropping, few cultivable lands having irrigation facilities, and low cropping intensity, low percent of women literacy, high concentration of scheduled tribe, and scheduled caste population. These are probably the factors that contribute to higher climate sensitivity coupled with low resilience and adaptive capacity in result in high climate vulnerability. The frequent occurrence of natural disasters in terms of drought due to climate vulnerability resulting in an extreme shortage of food and food security becomes a chronic issue resulting in a high burden of child and women malnutrition. Past studies observed that natural disasters had impacted the food security of people disproportionately (Duncan, Tompkins, Dash, et al., 2017; Mishra, 2017).

Climate vulnerability of Odisha has a close inter-association with agriculture production system through the gross cropped area and forest area which the past studies have also recorded (Mishra, Sahu, and Sahu, et al., 2015; Das, 2017) so far (Mishra, Sahu, and Sahu, 2015; Das, 2017). The empirical pieces of evidence establish that in Odisha, climate vulnerability has a significant role among factors that influence the agriculture production system and its consequent impacts on household nutrition status, particularly with children and women nutrition. Further, our observations have come up in the light of findings from one literature that confirms women's socioeconomic and biomarker status has a significant impact on the household child nutrition (Rachel, Levin, Hale, et al., 2020; Hoddinott, Alderman, Behrman, et al., 2013; Popkin, Horton, Kim, et al., 2001; Cook and Frank, 2008; Finucane, Stevens, Cowan, et al., 2011; Patnaik, Das and Bahinipati, 2016). Moreover, our findings also indicate that child nutrition status relates not only to socioeconomic factors but also to biophysical factors such as district's predisposition to gross cropped area, percentage of an area having forest coverage, annual rainfall, and irrigation facility along with the socioeconomic attributes such as women's social category and level of urbanization. Although the composite value of climate vulnerability does not have a greater role in predicting household nutrition directly, the individual level factors play a crucial role in determining household nutrition. Findings also reveal that gross cropped area, availability of forest areas, and average annual rainfall are negatively associated with household child wasting and are positively associated with area under irrigation and cropping intensity. Our study has found out that districts having good cropping pattern or cropping intensity generally have high agriculture production and better women's biomarker indicators such as anemia which is positively associated with the household child nutrition status.

The Odisha government has recently formulated Odisha State Agriculture Policy - "SAMBRUDHI-2020," where the emphasis has been laid on doubling of farmers' income by promoting farmer-friendly agriculture programs. The document also highlights the promotion of nutritional crops by changing cropping pattern from staple grain dominant system to non-staple diversified cropping system. The document also echoes the role of the climate-smart agriculture system. It also initiates action toward the promotion of climate-resilient crops and varieties along with pro-poor climate policies with adaptation strategies for agriculture.

This study has some limitations as it has drawn the inferences analyzing different secondary data sources. Hence, the exact prediction and interpretation need caution. The limitation of the accuracy and precision of the secondary data sources along with the availability in timeliness is another point of concern.

\section{Conclusions}

It has been observed that due to the diverse agro-climatic conditions of Odisha, there prevails a great extent of variations in the climate vulnerability among the districts in the result of a high impact on the production system. Bhadrak (0.193), 
the most vulnerable district followed by Sonepur $(0.191)$ and Baudh $(0.190)$ in terms of climate vulnerability on agricultural production and ecosystem, which are characterized with low socioeconomic development induces with a high concentration of scheduled caste population. Around 37\% (11 from 30) of districts of Odisha are categorized under high climate vulnerability range, $53 \%$ are in the medium range followed by $10 \%$ in the lower segment. These vulnerable high districts do score poorly both on biophysical as well as on socioeconomic aspects, i.e., few areas available with the districts for extensive cropping with less cultivable lands having irrigation facilities. Attributes such as low cropping intensity and a high concentration of scheduled caste population coupled are primary contributors to higher vulnerability. Similarly, less per-capita income and few person-days generated through assured employment generation schemes have also contributed to the higher vulnerability of districts. This creates more sensitivity to climate shocks and high reliance on fragile agriculture production ecosystem.

Empirical evidence also indicates that household nutrition status not only results from socioeconomic factors but also relates to biophysical factors of climate vulnerability attribute such as gross cropped area, percentage of area under forest coverage, cropping intensity, average annual rainfall, and irrigation facilities. The findings of the study are in congruence with past studies that agriculture as an intervention has a strong potential capacity to influence household nutrition outcomes by improving household food availability, to access and to improve dietary quality, income, and childcaring practice empowering the women (Black, Victora, Walker, et al., 2013; Paolisso, Hallman, Haddad, et al., 2002; Mishra, Sahu and Sahu, 2015; Das 2017; Lloyd, Kovats and Chalabi, 2011). The socioeconomic factors such as women's social and economic status quo, per-capita income, and level of urbanization also have significant roles to contribute as far as household nutrition outcomes are concerned. This has been established both in correlation and regression analyses. Of course, the study finds that in estimating (both woman and child) household nutrition status, the composite value of the climate vulnerability index does not influence much to predict the predictors. Still, individual covariates play a more predictive role in determining the household nutrition status such as gross cropped area, forest areas, and concentration of scheduled caste population.

Further, analyzing the evidence, the study suggests that climate vulnerability has a much more significant role in influencing the agriculture production system through gross cropped area and area under irrigation and district-wise forest coverage. These are the factors that have a much more significant role in influencing household nutrition through the agricultural production system by making the availability of quality food and diet. Availability and accessibility of quality food have a greater role in addressing the problem of malnutrition in India and particularly in Odisha. For solving this challenge, there is an emergent need for strong committed and concentrated effort, especially to link production of food with its nutritional quality, safety, delivery, and last-mile availability also affordability with other determinants of nutrition. Given this, in the year 2015, the Government of Odisha has prepared Odisha Nutrition Action Plan (ONAP) which is a multi-sector plan keeping in mind the Sustainable Development Goals and World Health Assembly targets for nutrition. The state has also set a target to achieve a 20\%-point reduction in malnutrition by 2025 (GoO, 2015). Special efforts have also been emphasized to address this problem through multiple interventions with a multidisciplinary approach and interdepartmental convergence at the government level instead of focusing on compartmentalized operations. Convergence in policies and actions would be required to ameliorate the present situation of undernutrition in the state with much more targeted interventions and strategies for certain vulnerable pockets.

\section{Acknowledgment}

The author wish to extend thanks to the unanimous reviewer of this article, their honest feedback and suggestions help us to strengthen the article.

\section{Authors' Contributions}

Arabinda Acharya, conceptualized, designed the research, and undertook the analysis and wrote the paper. Both the authors edited and approved the final paper.

\section{Conflicts of Interest}

We are declaring that "No conflicts of interest."

\section{Source of Funding}

No funding has received from any sources to undertake this study. 


\section{Ethics}

Not required.

\section{Availability of Supporting Data}

Data utilized to this paper is from secondary sources and available to public.

\section{References}

Black RE, Victora CG, Walker SP, Bhutta ZA, Christian P and de Onis M. (2013). Maternal and Child Undernutrition and Overweight in Low-income and Middle-income Countries. Lancet, 382:427-51.

Chhotray V and Few R. (2012). Post-Disaster Recovery and Ongoing Vulnerability: Ten Years after the Super-Cyclone of 1999 in Orissa, India. Global Environmental Change, 22(3):695-702.

Cook JT and Frank DA. (2008). Food Security, Poverty, and Human Development in the United States. Annals of the New York Academy of Sciences, 1136(1):193-209.

Das M. (2017). Impact of Climate Change on Agriculture Yield: Evidence from Odisha, India. International Journal of African and Asian Studies, 38:58-65.

Department of Agriculture and Farmers Empowerment. (2017). Report on Rejuvenation of Agriculture, Recommendations of State Level NITI Aayog Task Force. Odisha: Government of Odisha.

Department of Science and Technology. (2019). Report on Climate Vulnerability Assessment for the Indian Himalayan Region. New Delhi: Government of India.

Duncan J, Tompkins E, Dash J and Tripathy B. (2017). Resilience to Hazards: Rice Farmers in the Mahanadi Delta. India. Ecology and Society, 22(4):3.

Finucane MM, Stevens GA, Cowan MJ, Danaei G, Lin JK, Paciorek CJ, Singh GM, Gutierrez HR, Lu Y, Bahalim AN, Farzadfar F, Riley LM and Ezzati M. (2011). National, regional, and global trends in body mass index since 1980: Systematic analysis of health examination surveys and epidemiological studies with 960 country-years and 9.1 million participants. Lancet, 377(9765):557-567.

Global Nutrition Report. (2018). Available from https://www.globalnutritionreport.org/reports/global-nutrition-report-2018. [Last accessed on 2019 Oct 20].

GOI. (2004). Disaster management in India a Status Report. National Disaster Management Division. India: Ministry of Home Affairs, Government of India.

GOI. (2012). Disaster Management in India. Under the GOI-UNDP Project on Disaster Risk Reduction Program (2009-2012). India: Ministry of Home Affairs, Government of India.

GoO. (2016). State Disaster Management Plan. Orissa State Disaster Management Authority (OSDMA). Bhubaneswar: Government of Odisha.

Hoddinott J, Alderman H, Behrman JR, Haddad L and Horton S. (2013). The Economic Rationale for Investing in Stunting Reduction. Maternal Child Nutrition, 9(Supp 2):69-82.

Horton S and Steckel R. (2013). Malnutrition: Global Economic Losses Attributable to Malnutrition 1900-2000 and Projection to 2050. In: Lomborg B, editor. The Economics of Human Challenges. Cambridge, UK: Cambridge University Press.

International Food Policy Research Institute. (2014). Global Nutrition Report. Washington, DC: Actions and Accountability to Accelerate the World's Progress on Nutrition.

International Institute for Population Sciences. (2005-06). National Family Health Survey-3, 2005-06. Mumbai, India: Government of India. International Institute for Population Sciences. (2015-16). National Family Health Survey-4, 2015-16. Mumbai, India: Government of India.

Lloyd SJ, Kovats RS and Chalabi Z. (2011). Climate Change, Crop Yields, and Undernutrition: Development of a Model to Quantify the Impact of Climate Scenarios on Child Undernutrition; Public Media Environ Health Prospect, 119(12):1817-23.

Malik SM, Awan H and Khan N. (2012). Mapping Vulnerability to Climate Change and its Repercussions on Human Health in Pakistan. Globalization and Health, 8:31. 
Ministry of Earth Science. (2017). India Metrological Department, Government of India for Different Years. Available from: http:// www.imd.gov.in/pages/city_weather_main.php. [Last accessed on 2019 Sep 12].

Mishra D, Sahu NC and Sahu D. (2015). Impact of Climate Change on Agriculture Production of Odisha (India): A Ricardian analysis. Regional Environmental Change, 16(2):58-65.

Mishra PK. (2017). Socio-Economic Impacts of Climate Change in Odisha: Issues, challenges and Policy Options. Journal of Climate Change, 3(1):93-107.

Mishra S. (2007). Household Livelihood and Coping Mechanism during drought among Oraon Tribe of Sundargarh District of Orissa. India. Journal of Social Sciences, 15(2):181-6.

Mishra, D and Sahu NC. (2014). Economic Impact of Climate Change on Agriculture Sector of Costal Odisha. Vol. 10. Berlin: Elsevier. p241-245.

Paolisso MJ, Hallman K, Haddad L and Regmi S. (2002). Does Cash Crop Adoption Detract from Child Care Provision? Evidence from Rural Nepal, Economic Development. Culture Change, 50(2):313-338.

Patel SK, Mathew B, Nanda A, Mohanty B and Saggurti N. (2020). Voices of Rural People: Community-level Assessment of Effects and Resilience to Natural Disasters in Odisha, India. International Journal of Population Studies, 6(1):3-15.

Patel SK, Mathew B, Nanda A, Pati S and Nayak H. (2019). A Review on Extreme Weather Events and Livelihood in Odisha, India. Mausam, 70(3):551-60.

Patel SK. (2016). Climate Change and Climate-Induced Disasters in Odisha, Eastern India: Impacts, Adaptation and Future Policy Implications. International Journal of Humanities and Social Science Invention, 5(8):60-3.

Patnaik U, Das PK and Bahinipati CS. (2016). Coping with Climatic Shocks: Empirical Evidence from Rural Coastal Odisha, India. Global Business Review, 17(1):161-75.

Patt AG, Tadross M, Nussbaumer P, Asante K, Metzger M, Rafael J, Goujon A and Brundrit G. (2010). Estimating Least-developed Countries' Vulnerability to Climate Related Extreme Events over the Next 50 Years. Proceedings of the National Academy of Sciences of the United States of America, 107(4):1333-1337.

Popkin BM, Horton S, Kim S, Mahal A and Shuigao J. (2001). Trends in Diet, Nutritional Status, and Diet-related Noncommunicable Diseases in China and India: The Economic Costs of the Nutrition Transition. Nutrition Review, 59:379-90.

Rachel N, Levin C, Hale J, Hutchinson B. (2020). Double Burden of Malnutrition 4- Economic Effects of the Double Burden of Malnutrition. Lancet 395:156-64.

Radhakrishnan K, Sivaraman I, Jena SK, Sarkar S and Adhikari S. (2017). A Climate Trend Analysis of Temperature and Rainfall in India. Climate Change and Environmental Sustainability, 5(2):146-53.

Ray-Bennett NS. (2009). Multiple Disasters and Policy Responses in Pre-and Post-independence Orissa, India. Disasters, $33(2): 27490$. Registrar General of India. (2011). Census of India-2011. New Delhi India: Government of India.

Samuel SM, Smith MR and Guth S. (2017). Climate Change and Global Food Systems: Potential Impacts on Food Security and Undernutrition. Annual Review of Public Health, 38:259-77.

Sharma R, Mohanty A and Islam SS. (2016). Impact of Climate Induced Natural Disasters in Costal Odisha Focused on Socio-Economic Vulnerability. MOJ Cell Science and Report, 3(5):146-51.

The Intergovernmental Panel on Climate Change. (2007). $4^{\text {th }}$ Assessment Report, Working Group-II. United Nations: United Nations Environment Programme.

The Intergovernmental Panel on Climate Change. (2014). $5^{\text {th }}$ Assessment Report, Impact Adoptions and Vulnerability. United Nations: United Nations Environment Programme.

United Nations Children's Fund. (1990). Strategy for Improved Nutrition of Children and Women in Developing Countries. New York: United Nations Children's Fund. Available from: http://www.unicef.org/nutrition/files/UnicefNutritionStrategy.pdf. [Last accessed on 2019 Sep 30].

United Nations Children's Fund. (2006). Progress for Children: A Report Card on Nutrition, Number-4. New York: United Nations Children's Fund. Available from: http://www.unicef.org/publications/files/Progress for Children No.pdf.

Women and Child Development Department. (2015). Nutrition in Odisha, Time to Act together is now Odisha Multi-Sectoral Nutrition Action Plan (2017-2020). Odisha: Government of Odisha. 


\section{Appendix}

Table A1. District-wise selected indicators of Odisha, India.

\begin{tabular}{|c|c|c|c|c|c|c|c|c|c|c|c|c|c|}
\hline District & A & B & $\mathrm{C}$ & D & $\mathbf{E}$ & F & G & $\mathbf{H}$ & I & $\mathbf{J}$ & K & M & $\mathbf{N}$ \\
\hline Angul & 199 & 68.64 & 48 & 42.6 & 1262 & 301.46 & 168 & 40516 & 13.18 & 18.81 & 14.1 & 16.2 & 121.18 \\
\hline Balasore & 609 & 72.28 & 45 & 8.7 & 1631 & 322.2 & 169 & 20032 & 16.87 & 20.62 & 21.1 & 12.0 & 282.88 \\
\hline Baragarh & 253 & 65.38 & 60 & 20.9 & 1274 & 473.01 & 142 & 19404 & 10.38 & 20.17 & 11.9 & 10.9 & 278.84 \\
\hline Bhadrak & 601 & 75.83 & 48 & 4.0 & 1348 & 235.92 & 139 & 18217 & 17.32 & 22.23 & 19.0 & 10.1 & 195.29 \\
\hline Bolangir & 251 & 53.5 & 97 & 23.4 & 1262 & 489.43 & 168 & 20689 & 37.01 & 17.88 & 12.6 & 4.7 & 148.50 \\
\hline Boudh & 142 & 59.79 & 57 & 41.3 & 1161 & 138.3 & 163 & 17941 & 9.03 & 23.79 & 2.0 & 12.3 & 88.53 \\
\hline Cuttack & 666 & 79.55 & 56 & 20.1 & 1545 & 303.11 & 193 & 30898 & 11.6 & 19.0 & 3.6 & 27.9 & 282.89 \\
\hline Deogarh & 106 & 83.05 & 60 & 53.1 & 1214 & 108.53 & 175 & 23310 & 6.8 & 16.67 & 35.3 & 7.2 & 47.02 \\
\hline Dhenkanal & 268 & 71 & 67 & 39.1 & 1537 & 261.42 & 195 & 24920 & 11.69 & 19.62 & 13.6 & 9.8 & 203.48 \\
\hline Gajapati & 133 & 43.18 & 56 & 57.0 & 1283 & 150.2 & 198 & 23234 & 17.59 & 19.14 & 54.3 & 12.3 & 43.50 \\
\hline Ganjam & 429 & 61.13 & 56 & 38.4 & 1378 & 704.38 & 181 & 24287 & 69.62 & 19.5 & 3.4 & 21.8 & 382.82 \\
\hline Jagatsinghpur & 681 & 80.63 & 48 & 7.8 & 1427 & 177.23 & 197 & 25851 & 7.63 & 21.83 & 0.7 & 10.2 & 134.03 \\
\hline Jajpur & 630 & 73.29 & 48 & 24.8 & 1483 & 279.5 & 198 & 23056 & 8.01 & 23.72 & 8.3 & 7.4 & 207.46 \\
\hline Jharsuguda & 274 & 70.73 & 42 & 9.6 & 1294 & 80.98 & 133 & 32899 & 7.06 & 18.05 & 30.5 & 39.9 & 30.57 \\
\hline Kalahandi & 199 & 46.68 & 54 & 32.1 & 1401 & 616.86 & 184 & 19409 & 35.74 & 18.17 & 28.5 & 7.8 & 307.88 \\
\hline Kandhamal & 91 & 51.94 & 82 & 71.2 & 1425 & 188.54 & 176 & 29972 & 37.37 & 15.76 & 53.6 & 9.9 & 52.88 \\
\hline Kendrapara & 545 & 78.96 & 58 & 9.5 & 1495 & 262.55 & 194 & 17646 & 11.69 & 21.51 & 0.7 & 5.8 & 215.59 \\
\hline Keonjhar & 217 & 58.28 & 53 & 37.3 & 1370 & 393.33 & 161 & 30419 & 52.78 & 11.62 & 45.5 & 14.0 & 156.51 \\
\hline Khordha & 799 & 81.61 & 67 & 22.1 & 1664 & 207.36 & 192 & 36088 & 7.70 & 13.21 & 5.1 & 48.1 & 150.67 \\
\hline Koraput & 156 & 38.55 & 48 & 21.3 & 1531 & 400.34 & 147 & 26235 & 33.38 & 14.25 & 50.6 & 16.4 & 199.84 \\
\hline Malkangiri & 106 & 38.28 & 48 & 57.9 & 1696 & 230.8 & 170 & 16327 & 10.24 & 22.55 & 57.8 & 8.0 & 128.94 \\
\hline Mayurbhanj & 241 & 52.71 & 47 & 42.1 & 1110 & 491.81 & 138 & 20860 & 116.71 & 7.33 & 58.7 & 7.7 & 272.37 \\
\hline Nuapada & 230 & 44.76 & 50 & 46.5 & 1800 & 289.65 & 160 & 14438 & 26.38 & 13.46 & 55.8 & 7.2 & 86.53 \\
\hline Nabarangpur & 247 & 35.8 & 60 & 53.5 & 1469 & 242.27 & 192 & 16532 & 15.26 & 14.53 & 6.1 & 8.3 & 96.60 \\
\hline Nayagarh & 157 & 72.05 & 49 & 48.1 & 1046 & 290.75 & 156 & 20107 & 15.55 & 14.17 & 33.8 & 5.6 & 104.42 \\
\hline Puri & 488 & 78.28 & 75 & 4.0 & 1366 & 256.04 & 191 & 20120 & 6.05 & 19.14 & 0.4 & 15.6 & 259.41 \\
\hline Rayagada & 136 & 39.19 & 58 & 39.7 & 1261 & 268.86 & 168 & 22376 & 22.82 & 14.41 & 56.0 & 15.4 & 97.61 \\
\hline Sambalpur & 158 & 67.93 & 47 & 54.5 & 1383 & 273.22 & 153 & 33662 & 18.14 & 18.43 & 34.1 & 29.8 & 130.11 \\
\hline Sonepur & 279 & 64.04 & 49 & 17.5 & 1325 & 230.38 & 190 & 17446 & 10.16 & 25.6 & 9.4 & 7.7 & 148.43 \\
\hline Sundargarh & 214 & 65.48 & 47 & 51.1 & 1314 & 385.64 & 136 & 31622 & 48.07 & 9.16 & 50.8 & 35.5 & 149.97 \\
\hline
\end{tabular}

A-Population density, B-Female literacy rate, C-Infant mortality rate, D-Forest area, E-Average annual rainfall, F-Gross cropped area, G-Cropping intensity, H-Per-capita income, I-Average Man-days generated through MGNRESG, J-Scheduled caste population, K-Scheduled tribe population, L-Percent of Urban, M-Area under irrigation 